\title{
Tipsy with Water: Emerson’s Poetic Intoxication
}

Yves GARDES, Université de Rouen Normandie

DOI: $10.3917 /$ RFEA.156.0031

"So the poet's habit of living should be set on a key so low and plain, that the common influences should delight him. His cheerfulness should be the gift of the sunlight; the air should suffice for his inspiration, and he should be tipsy with water." (Essays 461)

In "The Poet," Emerson applies himself to describing the poet whom he looks for in vain (Essays 465). The ideal poet is first opposed to common men, then portrayed as what common men are not, and finally opposed to traditional poets, or, as Emerson likes to call them, "men of poetical talent" (Essays 450). One of the features ascribed to men of poetical talent in the essay is their propensity to inebriate themselves with wine. Dionysian intoxication operates as a psychotrope, inasmuch as it alters the individual's consciousness and, in the case of the man of poetical talent, adds "this extraordinary power to [his] normal powers" (Essays 460). In Emerson's view, wine is not the only psychotrope that the ordinary poet has at hand: "[...] bards love wine, mead, narcotics, coffee, tea, opium, the fumes of sandal-wood and tobacco [...]", but they are all "substitutes for the true nectar" (Essays 460). However appealing alcohol or opiates may be, they provide a "spurious mode of attaining freedom" (Essays 460) that distracts the intellect from "coming nearer to the fact" (Essays 460).

Such conclusions on psychotropic substances lead Emerson to advocate a peculiar form of teetotalism: "[The ideal poet] should be tipsy with water" (Essays 461). Emerson does not so much recommend total abstinence from alcoholic drink, as he does suggest intoxication with water: a transparent, colorless, tasteless and odorless-a pure-liquid, and necessary condition to life itself. Thus, Emerson seems to challenge the habits of intoxication of Samuel Taylor Coleridge and Thomas De Quincey, who saw opium as a means to ease, if not to cure, headache, neuralgia and hunger among other afflictions, at a time when the drug was readily available (Cooke 26-28). In other words, Emerson appears to oppose Alfred de Musset's famous line- "Never mind the bottle, as long as it gets you drunk." (Shapiro 543) —and to offer his own version: "do mind the bottle, drink water."

In this paper, I intend to account for Emerson's ambivalence to intoxication and to shed light on Emerson's theory of poetic experience. First, I want to argue that Emerson only dismisses psychotropes as such because the spurious effects they induce on the poet's intellect go against the very act of poetic practice-in Emerson's view, poiesis is far superior to mimesis, for it allows the poet to come "nearer to the fact." Then, I shall question Emerson's paradoxical call for intoxication: if Emerson takes a stand against psychotropes, why does he subscribe to the necessity of intoxication? What does it mean to be "tipsy with water"? Is Emerson suggesting an alternate and yet genuine form of intoxication, or is he subverting the concept of intoxication in order to reconcile it with teetotalism? Finally, I shall argue that Emerson's updated theory of poetic intoxication has epistemological consequences on the conception of poetry. 


\section{The spurious effects of psychotropes}

Emerson has an extensive understanding of psychotropes and divides them in "The Poet" into different categories. The first cluster, as quoted above, includes chemical psychotropes whose properties influence body and mind when ingested or inhaled: "wine, mead, narcotics, coffee, tea, opium, the fumes of sandal-wood and tobacco" (Essays 460). Strikingly enough, Emerson considers these chemical psychotropes as parts of one and the same group: he makes no distinction between stimulants (coffee, tea or tobacco) and depressants (wine, narcotics, opium and fumes of sandalwood); he does not deem worthwhile to discriminate stronger drugs (opium or narcotics) from softer ones (tea or the fumes of sandal-wood); and he fails to comment on any of these drugs' potentially addictive quality. The swift enumeration of these psychotropes contributes to shaping the reader's feeling that all these drugs are alike and merely "add [...] extraordinary power to [...] normal powers" (Essays 460). In opposing the singular "extraordinary power" to the plural "normal powers," Emerson subsumes the different effects of chemical psychotropes into a single power-as understood in the literal sense of "extraordinary" — against man's regular powers deriving from his senses - sight, hearing, smell, taste and touch. This is to say that this "extraordinary power" smoothes out the productivity of "normal powers" and amounts to one and the same ability: poets intoxicated with chemical psychotropes are doomed to produce similar verses.

Addiction to drugs implicitly appears, however, in men's deliberate pursuits of exhilaration. Shifting from chemical drugs to intellectual psychotropes, Emerson sees in social activities the same exhilarating potential as in chemicals: "All men avail themselves of such means as they can, to add this extraordinary power to their normal powers; and to this end they prize conversation, music, pictures, sculpture, dancing, theatres, travelling, war, mobs, fires, gaming, politics, or love, or science" (Essays 460). Once again, Emerson refrains from distinguishing between plain social interactions (conversation, travelling or gaming), esthetic ones (music, pictures, sculpture, dancing or theatres) and morally engaging activities (politics, war or mobs). With this new enumeration, Emerson reduces the intensity of each activity and absorbs them all as equivalent "means," thus focusing the reader's attention on the process through which exhilaration is achieved, rather than on the state that the individual ends up in.

Emerson even notes that a certain class of people have made a profession out of this obsessive and addictive search for psychotropes and the pleasure they actuate in people: "Hence a great number of such as were professionally expressors of Beauty, as painters, poets, musicians, and actors, have been more than others wont to lead a life of pleasure and indulgence; [...] and, as it was a spurious mode of attaining freedom, [...] they were punished for that advantage they won, by a dissipation and deterioration" (Essays 460). Emerson specifically targets professionals of the artistic community, for they have fooled themselves in their works ("deterioration") and surrendered to mere distraction ("dissipation"), but denies his own membership in this socio-professional class, as he voices a certain clarity of thought in a gnomic sentence: "But never can any advantage be taken of nature by a trick" (Essays 460).

If "The Poet" falls short of explaining this "trick," the last essay of The Conduct of Life dwells on the details of a similar sort of deceit. Indeed, in "Illusions," Emerson relates an afternoon he spent in the Mammoth Cave in Kentucky, an experience we may compare with that of chemical intoxication, for it also produces a "trick," or rather, an illusion. In the incipit, the cave seems to operate as a topological psychotrope and disrupts the narrative of the essay's opening lines: 
I saw high domes, and bottomless pits; heard the voice of unseen waterfalls; paddled three quarters of a mile in the deep Echo River, whose waters are peopled with the blind fish; crossed the streams "Lethe" and "Styx;" plied with music and guns the echoes in these alarming galleries; saw every form of stalagmite and stalactite in the sculptured and fretted chambers,-icicle, orange-flower, acanthus, grapes, and snowball. We shot Bengal lights into the vaults and groins of the sparry cathedrals, and examined all the masterpieces which the four combined engineers, water, limestone, gravitation, and time, could make in the dark (Essays 1115).

Given the density of the rhetorical devices used in this passage, a certain poetic quality may be acknowledged. First, the initial subject "I" reigns over a series of predicates ("saw," "paddled," "crossed," "plied," "saw") separated by semi-colons that do not merely suggest a consecution of actions, but rather a simultaneity. The accumulation of these verbs, conjugated however in the past tense, conveys a feeling of immediacy that challenges the narrative's expected developmentEmerson announces a "long summer day" (Essays 1115) and renders this timeframe in two sentences. The reader does not so much follow the same path as Emerson in the cave as he pictures the time spent there as one idiosyncratic experience. However brief his depiction of the day in the cave is, Emerson does not dismiss his inclination for bipolar pairs: "high domes" are opposed to "bottomless pits"; blindness and the absence of vision ("unseen," "blind") echo the place's cacophony and saturation of sounds ("voice," "music," "guns," "echoes"); "stalagmites" are inevitably paired with "stalactites." All these oppositions diffract the cave's dimensions, hinting at the magnificence of the scenery and, in turn, reducing the radiance of the subject "I," relegated to the passage's beginning. On this account, the subject "I" could be interpreted as undergoing the same metamorphosis at work in the aposiopesis of the extract: "-icicle, orange-flower, acanthus, grapes, and snowball." The lost subject resurfaces in the dissection of the noun "icicle" into an "I" now qualified by spherical features implicitly suggested by the graphic reminiscence of "cycle." The metamorphosis takes the form of vegetable blooming from a single flower ("orange-flower"), to a multitude ("acanthus"), then to the ripe fruits of the gods ("grapes"). This conversion from the singular to the plural results in a "snowball," a spherical object made of infinite snowflakes - that is, infinitesimal icicles-, which is bound to thaw into water: the experience in the cave allows the shift from an active and yet evanescent pronoun "I" to a contemplative and unlimited "we" in the second sentence. Indeed, after "shooting Bengal lights," the pronoun "we" witnesses the works of four personified "engineers": a chemical substance ("water") and a sedimentary rock ("limestone"), a physical law ("gravitation") and a transcendental category ("time"), which together produce "masterpieces" beyond human authorship.

This passage lets it be known, however, that the experience in the cave is only an illusion. The quotation marks surrounding the nouns "Lethe" and "Styx" evidently suggest that Emerson did not cross the mythical streams, and point to the symbolic appeal of the lake and river. What confirms this illusion is that these names are not given by Emerson himself in a moment of poetic inspiration, but by the national park which organizes different recreational tours in the cave. ${ }^{1}$ The "recreation"-in a literal sense-or, extensively, the staging of this experience, is precisely what Emerson denounces in the following paragraph:

${ }^{1}$ The "River Styx Cave Tour" and the "Star Chamber Tour" (referred to later in the essay "Illusions") are two different tours that tourists can still take today when visiting the Mammoth Cave National Park. They last two and a half hours. 
The mysteries and scenery of the cave had the same dignity that belongs to all natural objects, and which shames the finne things to which we foppishly compare them. I remarked, especially, the mimetic habit, with which Nature, on new instruments, hums her old tunes, making night to mimic day, and chemistry to ape vegetation. But then I took notice, and still chiefly remember, that the best thing which the cave had to offer was an illusion (Essays 1115).

These lines are semantically saturated with the vocabulary of illusion: the "mysteries and scenery" point to the inauthentic and esthetic quality of a play, which deceives the spectator ("shames" and "foppishly"). Emerson targets nature for its "mimetic habit" to "mimic" and "ape" itself with ever renewed means. Nature's parody of itself is the very reason why the topological psychotrope of the cave misleads the beholder: it distracts the individual's attention from some authentic perception of nature, from that primary source from which teachings may be drawn. Thus Emerson rejects this representational model, for the esthetic conversion drains the truth of the object and replaces it with artificialities: "I own, I did not like the cave so well for eking out its sublimities with this theatrical trick" (Essays 1116).

This fool's game is precisely what Emerson calls an "illusion," and it is "the best thing" which can be drawn from the cave's experience. Identifying this, Emerson notes that one easily gives in to circumstantial pleasure: "Our first mistake is the belief that the circumstance gives the joy which we give to the circumstance" (Essays 1116). Joy is not given by circumstance, but is instead projected by the individual into circumstance: the individual's agency in the experience makes up for the lack of "true" exhilaration. In other words, tourists who visit the cave have a preconception of the marvels they are to witness, and the cave only operates as the psychotrope whose spurious effect is to let loose the intellectual projection.

However artificial the effects of psychotropic substances may be, Emerson does not disregard the process of intoxication. Construed as Platonic cave, the intellect does not allow the individual to access a higher state of consciousness. Nor do traditional psychotropes assist the intellect in its emancipation. And yet, Emerson places confidence in a peculiar substance, in a "true nectar," which is nothing else than water.

\section{The true nectar: water}

In "The Poet," Emerson acknowledges the need of the intellect for some sort of assistance in its "release," so that the poet may speak "adequately":

The poet knows that he speaks adequately, then, only when he speaks somewhat wildly, or, "with the flower of the mind;" not with the intellect, used as an organ, but with the intellect released from all service, and suffered to take its direction from its celestial life; or, as the ancients were wont to express themselves, not with intellect alone, but with the intellect inebriated by nectar. (Essays 459-460)

The intellect as such, described as a prison cell and a "dark chamber" in "Intellect," does not allow the poet to speak truly. A servant to his thoughts, the poet may not access new thoughts if he attempts to seize them. Therefore, the intellect requires a stimulus, expressed in the inebriation "by nectar." The challenge remains, however, to identify what Emerson means by this enigmatic "nectar," found nowhere else in Emerson's essays except in "Fate," in another usage of the term. 
One of his poems may, however, offer an explanation or at least interpretation. "From the Persian of Hafiz" was a late addition to Poems, published in 1847 . Indeed, the poem is a translation of "Sakiname, des Buch der Schenken," from Joseph von Hammer's German translation of Hafiz, Der Diwan von Mohammed Schemsed-din Hafis, a book Emerson acquired in 1846 (Variorum 255). The number of lines Emerson edited in the poem is remarkable, and one change in particular may reveal Emerson's understanding of the term "nectar." The lines "Bring me, boy, the nectar cup / Since it leads to Paradise" of the London printer's copy are replaced with "Let flute and lyre lordly speak; / Lees of wine outvalue crowns" in the Boston printer's copy. But the first line of the London text ("Bring me, boy, the nectar cup") reappears further down in the Boston version-"Bring me, boy, the fire-water; - " which points to the equation between "nectar" and "fire-water" (Variorum 256, 261). Though the London edition was published before, there is no certainty however as to the priority of the term "fire-water" over that of "nectar." Nevertheless, this hesitation suggests Emerson's accepting of the term "nectar" as a psychotropic substance, equivalent to "fire-water." Emerson thus retains the psychotropic property of "fire-water," but translates it into "nectar," the drink of the gods.

However, the "nectar," fueled with the symbolic potential of divine effects, could paradoxically be interpreted as a traditional psychotrope that would operate in the same fashion as chemical substances do or, by extension, as the cave does. Not only does Emerson need to tune down the chemical properties of "fire-water," he must also reduce the symbolic value of the "nectar" in order to find the appropriate psychotrope for "true" intoxication. Hence, the poet "should be tipsy with water," (Essays 461), for water plays the part of an intoxicating substance which paradoxically does not induce the spurious effects of traditional psychotropes-a substance which does not smooth out the expressive potential of the senses, which prevents the "normal powers" from coalescing into one monotonous power whose effect is thus deemed "spurious," and which preserves the manifold expressions of the poet's innate powers.

At the cost of scientific approximation, water is symbolically construed as the primal psychotrope that elevates the dead body to a live state. This suggests that being alive is not the balanced state from which anyone attempts to depart through the use of traditional psychotropes; being alive is rather the exhilarated state in which water continuously maintains the body. If deprived of water, the body is left dying: "On the brink of waters of life and truth, we are miserably dying" (Essays 463). In other words, water is the natural habitat where life is made possible-where life started on Earth. Thus, home is where water is: "We never can part with it; the mind loves its old home [...]. It is firm water: it is cold flame: what health, what affinity!" (Essays 542) In the second sentence of this quotation from Emerson's second essay entitled "Nature" (1844), the punctuation first works to mimic the effect of ebb and flow. The two colons signal a form of arrest, which scans the progress of the tide. On the one hand, the first colon points to the figure of double enclosure whereby opposites ("water" and "flame") seem to contain each other, thus creating a syntactic oxymoron in addition to the lexical one. On the other hand, the second colon relieves the water of this form of arrest and initiates a succession of thought which recalls water now running wild, the comma separating the two exclamations reinforcing the wavy effect of the anaphoric "what," and the exclamation mark celebrating the climactic exhilaration.

More generally in Emerson's essays, the semantic specter of water signals the promise of the poetic exhilaration of life. The instances in which the in uence of water is conveyed alternately take the form of ingestion and immersion. In the eponymous essay, Emerson defines the Over-Soul as "that flowing river, which, out of regions I see not, pours for a season its streams into me" (Essays 
385). In "The Poet," the intellectual man suffers "the ethereal tides to roll and circulate through him," and "he is caught up into the life of the Universe" (Essays 459). To Branka Arsić, Emerson turns fluxes, flows and streams into "a universal ontological and existential principle, [...]" (Arsić 5): in Nature, the river becomes the symbol of the "flux of all things" (Essays 21), in "Experience," the first cause is identified with a fluctuating movement (Essays 485), in "Self-Reliance," man is identified with an unstable oceanic being: "Man does not stand in awe of man, nor is his genius admonished to stay at home, to put itself in communication with the internal ocean, but it goes abroad to beg a cup of water of the urns of other men" (Essays 272). These repeated references to water operate as mooring posts to which Emerson's writing constantly returns after drifting away.

If the ingestion of, or the immersion in, water produce positive effects on the body however, submersion points to water's destructive quality. In his early lecture "Water" (1834), Emerson relates the substance's dual productivity:

But how is this continual loss and destruction repaired? [...] Avalanches fall but mountains do not grow as vegetables and animals. Iron rusts but new iron does not form along the ground. Diamond and granite decay under the wear and the chemical action of air and water but new diamond and new granite are not crystallized. How is all this waste repaired? By the waters. The same power that destroys in different circumstances is made to reproduce.

(Early Lectures, I, 55)

Destruction and repair go hand in hand as bipolar effects, and thus suggest that, for Emerson, water is not merely a psychotrope, but a genuine pharmakon. Both a poison and an antidote, water follows a cycle that alternately erodes and restores, according to the "circumstance." Furthermore, water derives its vital energy from its destructive potential: it works to "repair" what has been "lost" in the circular movement of life.

From his early lecture to the abundant occurrences of the flowing movement in his essays, Emerson never loses sight of the dual essence of water, and even devotes a manuscript poem to the topic. In the poem "Water," dated between 1840 and 1849, Emerson relates water's exhilarating as well as destructive power in these terms:

The Water understands

Civilization well-

It wets my foot, but prettily,

It chills my life, but wittily,

It is not disconcerted,

It is not broken-hearted,

Well used, it decketh joy,

Adorneth, doubleth joy;

Ill-used it will destroy

In perfect time and measure,

With a face of golden pleasure,

Elegantly destroy. (Collected Poems 377)

The second half of the poem does not elucidate what a "good" or "bad" use of water means, but insists on its positive and negative effects, thus confirming the liquid as a pharmakon. Water's exhilarating effect is signaled by the disyllable predicates "decketh," "adorneth," and "doubleth," which mimic its ebb and flow_- the ebb tide being suggested by the syllable ending with the voiceless dental fricative "-th," reminiscent of the retreat of water on sand. The ebb and flow is also hinted 
at in the addition of the object "joy" to the first verb, its retreat and absence after the second one, and its renewed addition to the last. On the other hand, the destructive power of water is intimated by the sententious tone of the last four lines. Destruction takes the form of a promise signaled by the modal "will": water will strike a surgical blow, with utmost precision ("In perfect time and measure"), and will prove blithesome in doing so ("With a face of golden pleasure").

These opposite effects are nevertheless toned down in the poem's first lines. Water's silver lining is identified in the modulation of its effects. The predicates "chills" and "wets," first read as negative effects, are modulated by the adverbs "prettily" and "wittily," which reduce the negative reach of the verbs: in the pendular movement of its identification, water is thus neutralized. This neutralization is also mirrored in the two litotes used to qualify water: "not disconcerted" and "not broken-hearted" point to a semantically negative emotion, which is grammatically denied, thus conferring to water a stable and neutral identity: "The wave moves onward, but the water of which it is composed does not." (Essays 281)

Transparent, colorless, tasteless, odorless, and now neutral and indifferent, water is characterized by divine attributes, and its ingestion may now be equated with transubstantiation:

The circulation of the water in the globe is no less beautiful a law than the circulation of blood in the body. [...] Of course these suspended waters are present in the air when it is most dry and transparent and we have not only a visible ocean at our feet but we are thus always bathed in an invisible ocean overhead, and around us. (Early Lectures, I, 63)

Equating the laws of the circulation of "water in the globe" to that of water "in the body," Emerson suggests that the ingestion of water unfolds a whole world within the body. As wine allows the communicant to become one with the divine, water allows the poet to become one with divine nature. If God is everywhere, so is water, in its "suspended" form in the air become an "invisible ocean overhead." This implied equation between God and water is reminiscent of Thales' cosmology, which has it that water is the first principle - that is, water, as a single material substance, is the originating principle of nature. Transubstantiation thus releases the true poets from the limitations of their bodies and allows "the flowing or metamorphosis" (Essays 456) that reunites them with the flux of nature: water is the true nectar, that transforms poets into "liberating gods" (Essays 461, 462).

\section{The ecstatic state of being alive}

In Emerson and the Conduct of Life, David Robinson observes that "Emerson recognized that he had an audience thirsty for a message of experiential religion, but [that] he had to witness to the vagaries as well as the availability of mystical ecstasy" (Robinson 29). In spite of the doubt that David Robinson casts on Emerson's "visionary experience" (Robinson 4) of ecstasy, his phrasing proves fortunate for our analysis of the psychotropic experience of hydration, or, less clinically, of transubstantiation. The "thirst" that David Robinson describes expresses the need, or rather addiction, to water, and may be interpreted as a belief in the psychotrope's rewarding effects. Thus ecstasy is a matter of conviction, and Emerson repeatedly refers to it in these terms. In "The Transcendentalist," Emerson "believes in inspiration, and in ecstasy" (Essays 196), and in 
"Illusions," he relates the "faith in ecstasy" (Essays 1061): ecstasy is believed to be the reward brought by "experiential religion." 2

However, religion should not be understood as "this or that doctrinal commitment or dogma" but rather construed "in the literal sense of 'relinking"' (Grimstad 67). Ecstasy is the state in which the individual is bound again to the whole, or rather, in which the individual is one with the whole. As expressed in the last sentence of "Thoughts on Modern Literature," religion "will bind again these that were sometime frivolous, customary, enemies, skeptics, self-seekers, into a joyful reverence for the circumambient Whole, and that which was ecstasy shall become daily bread" (The Dial 158). Faced with this prophetic sentence, the reader may feel trapped in a logical dead end: does "belief" fill in Emerson's aporetic theory of ecstasy and dismiss it in inexplicable mysticism, or does Emerson work out a pragmatic path to ecstasy? The answer most likely lies somewhere in between, and David Robinson is right to underline that Emerson's "fading of the visionary was never complete," his "pragmatic orientation [...] never absolute" (Robinson 3).

At the crossroads of these two orientations is Emerson's theory of poetic intoxication. Indeed, "poetic raptures" are equated with "ecstasy," as Emerson's comment on Plato's writing suggests: "He never writes in ecstasy, or catches us up into poetic raptures" (Essays 644). The symmetry between the mystical terming of "ecstasy" and the pragmatic materialization in "poetic raptures" points to a poetic means of accessing ecstasy. Another equation may be identified between the poet's "resigning himself to the divine aura which breathes through forms" (Essays 459) and "the currents of the Universal Being [circulating] through me" in the episode of the transparent eyeball (Essays 10). At the cost of a few syllogisms, the ecstatic state is achieved when the poet abandons himself to nature, that is, when he surrenders to the streams of nature, that is, to streams of water. In other words, the ecstatic state is reached when the poet has departed from himself, when he is finally absent from himself: "This path is difficult, secret and beset with terror. The ancients called it ecstasy or absence, — a getting out of their bodies to think." (Essays 663)

Thus the representational model for the ecstatic state resembles that of a more traditional stimulating psychotrope. Not only is the poet absent from himself, he may also experience different intensities in the effects of his intoxication: "The character and duration of this enthusiasm varies with the state of the individual, from an ecstasy and trance and prophetic inspiration,- - which is its rarer appearance,_- to the faintest glow of virtuous emotion" (Essays 392). Also, under the influence of poetic intoxication, his pupils are dilated:

The poet also resigns himself to his mood, and that thought which agitated him is expressed, but alter idem, in a manner totally new. The expression is organic, or, the new type which things themselves take when liberated. As, in the sun, objects paint their images on the retina of the eye, so they, sharing the aspiration of the whole universe, tend to paint a far more delicate copy of their essence in his mind. (Essays 458)

This "far more delicate copy" that objects paint on the retina points to the mydriasis of the eye, otherwise witnessed under the influence of a psychotropic stimulant. All symptoms-absence, variation in intensity and mydriasis — can be read as tangible evidence of poetic intoxication, and thus confirm Emerson's pragmatic explanation of ecstasy.

${ }^{2}$ David Robinson shows how this belief is challenged after Emerson's crisis in the year 1840 (Robinson 3). 
But one may still wonder if Emerson is presenting his reader with a literal form of intoxication, or if he is ironically advocating teetotalism. In fact, he challenges water's reputation for neutrality and purity, suggesting that the sober state which society acknowledges as such is in fact the ecstatic state that people have come to resist. Water's original effect is to exhilarate the body and bring it to life. But once accustomed to its effect, the individual no longer recognizes life as an exhilarated state. In his essay "Fate," Emerson writes: "The pleasure of life is according to the man that lives it, and not according to the work or the place. Life is an ecstasy" (Essays 963). What Emerson denounces here is people's constant search for pleasure and satisfaction while they fail to acknowledge the very fact that they are alive as absolute ecstasy. As one who looks for his glasses when they are sitting on his nose, the individual constantly works to improve the circumstances of his existence, hoping to experience ecstasy when it is already at hand: "Our first mistake is the belief that the circumstance gives the joy which we give to the circumstance. Life is an ecstasy" (Essays 1116).

The acknowledgement of ecstasy as the state of being alive could be interpreted as the disappointing climax of Emerson's theory of intoxication. But Sharon Cameron suggests instead that ecstasy consists in "the discovery of [...] radical commonness" (Cameron 6), that is, the discovery of the faintest details of natural objects that are otherwise overlooked. Water thus operates as a psychotrope on two levels. As a substance, it facilitates access to the ecstatic state of being alive, and favors the acknowledgment of this state; and as flux, it sustains the body in a constant exhilaration of "radical commonness." I understand Sharon Cameron's discovery of radical commonness as Stanley Cavell's "quest of the ordinary," which Sandra Laugier describes as a way to rethink the relationship between the self and the world, and explore the individual's ability, or inability, to render the world in ordinary, common language (Laugier 47). Water thus also stands for words, and the ongoing metaphor suggests that drinking water can be equated with reading poetry, or listening to an orator, as in "The American Scholar":

The orator distrusts at first the tness of his frank confessions, - - his want of knowledge of the persons he addresses, - until he finds that he is the complement of his hearers; - that they drink his words because he fulfils for them their own nature ; the deeper he dives into his privatest, secretest presentiment, to his wonder he finds, this is the most acceptable, most public, and universally true (Essays 64).

Words only produce exhilaration in their transaction between the orator and the hearer, that is, in the stream of consciousness - in the literal sense- from one individual to another. But for words to draw the hearer's attention, they should spurt out from the orator's most intimate "presentiment": from the common source that the orator and the hearer share.

Emerson's negative mention of chemical substances is thus offset by his strong interest in the process of intoxication itself, for it provides him with a faithful metaphor for poetic experience. The similarity between intoxication and poetic experience is presented through the prism of water: chemically a neutral substance, metaphorically an exhilarating one, water works as a psychotrope insofar as it elevates the body to the ecstatic state of being alive. Because poetic experiences are unabated occasions to acknowledge the ecstasy of life itself, Emerson's epistemology of poetic intoxication may account for his ongoing poetic practice throughout his literary career. 


\section{Works Cited}

Arsić, Branka. On Leaving: A Reading in Emerson. Cambridge: Harvard University Press, 2010.

Cameron, Sharon. "The Way of Life by Abandonment: Emerson's Impersonal." Critical Inquiry, vol. 25, n 1, Autumn 1998. 1-31.

Cavell, Stanley. In Quest of the Ordinary: Lines of Skepticism and Romanticism. Chicago: U. of Chicago Press, 1988.

Cooke, Michael G. "De Quincy, Coleridge, and the Formal Uses of Intoxication." Yale French Studies, n' 50, 1974. 26-40.

Emerson, Ralph Waldo. Essays \& Lectures. Joel Porte, ed. New York: The Library of America, 1983. -. Collected Poems and Translations. Harold Bloom and Paul Kane, eds. New York: The Library of America, 1994.

-. The Collected Works of Ralph Waldo Emerson. Vol. IX. Poems. A Variorum Edition. Albert J. von Frank and Thomas Wortham, eds. Cambridge: The Belknap Press of Harvard UP, 2011.

- The Early Lectures of Ralph Waldo Emerson. Vol. I: 1833-1836. Stephen E. Whicher and Robert E. Spiller, eds. Cambridge: Harvard UP, 1969.

- "Thoughts on Modern Literature." The Dial: A Magazine for Literature, Philosophy and Religion. Volume 1. Boston: E. P. Peabody, 1842.

Grimstad, Paul. “On Ecstasy: Sharon Cameron's Reading of Emerson.” American Impersonal. Essays with Sharon Cameron. Ed. Branka Arsić. New York: Bloomsbury Publishing Inc., 2014.

Laugier, Sandra. "Emerson: penser l'ordinaire." Revue française d'études américaines, n 91 , February 2002. 43-60.

Robinson, David M. Emerson and the Conduct of Life: Pragmatism and Ethical Purpose in the Later Work. Cambridge: Cambridge UP, 1993.

Shapiro, Fred R., ed. The Yale Book of Quotations. New Haven, Yale UP, 2006.

Warner, Nicholas O. "God's Wine and Devil's Wine: The Idea of Intoxication in Emerson." Mosaic: An Interdisciplinary Critical Journal, vol. 19, n 3, 1986. 55-68. 